\title{
The Impact of ICT Use on Loneliness and Contact with Others among Older Adults
}

\author{
Shelia R. Cotton ${ }^{1 *}$, William A. Anderson ${ }^{1}$, and Brandi M. McCullough ${ }^{1}$ \\ ${ }^{1}$ Department of Sociology, University of Alabama at Birmingham, Alabama, USA \\ *Corresponding author (cotten@uab.edu)
}

\begin{abstract}
Purpose Older adults are at increased risk of experiencing loneliness and depression, particularly as they move into different types of care communities. ${ }^{41}$ Information and communication technology (ICT) usage may help older adults to maintain contact with social ties. ${ }^{12,19,41}$ However, prior research is not consistent in whether ICTs increase or decrease isolation and loneliness among older adults. ${ }^{12,19,26,41}$ The purpose of this study is to examine how ICT use impacts the social isolation and loneliness of older adults in assisted and independent living communities. Method Data from an ongoing study of ICT usage among older adults in assisted and independent living communities in Alabama is used. Simple regression analyses were performed to determine the relationship between frequency of Internet use and isolation and loneliness. As the data comes from an intervention study (ICT training vs. No training), the analyses controlled for the arm of the study participants were in. Results \& Discussion Results from post intervention surveys show that going online more frequently was associated with lower levels of loneliness and isolation. Greater frequency of Internet use was associated with greater quantity and ease of contact with others. Using the Internet may be beneficial for decreasing loneliness and increasing social contact among older adults in assisted and independent living communities.
\end{abstract}

Keywords: older adults, loneliness, social contact, social isolation, ICT

\section{INTRODUCTION}

As individuals age, they may lose contact with social network members for a variety of reasons. This loss of contact is often associated with social isolation and loneliness. Some research has shown that information and communication technology (ICT) use may help to decrease social isolation and loneliness in older adults. The purpose of this study is to examine how frequency of going online among residents of independent and assisted living communities (AICs) is related to experiences of loneliness and social isolation.

\section{BACKGROUND}

The concepts of loneliness and social isolation are closely related concepts, yet highly nuanced. Loneliness is the subjective experience ${ }^{17,30}$ of negative feelings about levels of social contact ${ }^{38}$; otherwise stated, it is the involuntary state of social isolation, that is, the feeling of being alone. ${ }^{34}$ Loneliness does not stem solely from objective levels of contact, but rather results from the differences between the levels of need and desire for social relationships and the availability of relationships at hand. $^{31}$ Researchers using loneliness measures typically ask respondents whether they feel lonely, whether they do not see enough people, and whether they wish for more contact. ${ }^{38}$

Social isolation is the objective experience ${ }^{30}$ of the absence of contact with other people; more aptly stated, it is the absence of good support. ${ }^{38}$ Social isolation is simply the absence of meaningful social relationships or the experience of being alone. ${ }^{33}$

Older adulthood is often associated with higher rates of loneliness ${ }^{21,44}$ and social isolation. ${ }^{16}$ This occurs for a variety of reasons, including death of social ties, relocation to different types of living and care communities, and limitations in physical and mental health. In addition, age is negatively related to network size, closeness to network members and number of primary group ties. ${ }^{8} \quad$ Older African Americans are at the greatest risk of social isolation, ${ }^{25}$ along with childless individuals and widows $^{38}$ Those at risk for loneliness include older adults who have recently migrated following retirement, those caring for a dependent spouse, ${ }^{38}$ the chronically ill, ${ }^{16}$ those living alone,${ }^{34}$ and females living in rural communities. ${ }^{44}$ Although the likelihood of experiencing loneliness does increase with age, only a minority of older people continuously suffer from loneliness. A noteworthy finding is that loneliness does not increase simply because of additional years, but because of an increase in disability and a decrease in social integration. ${ }^{21}$ The only risk factors applying to both the socially isolated and lonely are living alone and having low life satisfaction. ${ }^{16}$ In sum, predictors of social isolation and loneliness are not necessarily interchangeable, ${ }^{16}$ which demonstrates the need for researchers to distinguish between the two concepts.

Older adults are at risk for increases in loneliness and social isolation, particularly for those who move 
to different types of care communities. Research shows that older adults who move into assisted and independent living communities are likely to experience reduced quality of life. ${ }^{39}$ They are likely to experience loss of social connections, physical separation from familiar places and routines, and resulting emotional distress that can combine to affect the mental and physical health of residents. ${ }^{39}$ One possible way to counteract these effects is the use of ICTs to help maintain social contact with social network ties.

\section{ICT USE, CONTACT WITH OTHERS, AND LONELINESS AMONG OLDER ADULTS}

ICT use enables older adults to stay in contact with others and communicate with their loved ones. ${ }^{2}$ Email, for example, is more effective than in-person or phone communication for facilitating regular contact with family and friendship networks. ${ }^{4,11,13,27,}$ 37, 42 A wealth of research indicates that ICT use by older adults can both strengthen and expand their social networks and social connections, 3, 4, 5, 14, 15, 19, $22,27,28,29,35,39,40$ with relationships taking place both on and offline. ${ }^{3}$ ICT use can also reduce the impact of geographic distance for older adults, ${ }^{1,39}$ with dispersed families increasingly using ICTs as the primary conduit through which they sustain generational bonds. ${ }^{6}$

Whether ICT use increases or decreases social isolation is not clear-cut, however. ICT has been shown to be associated with a decrease in social isolation and increases in social connectivity among older adults. ${ }^{1,3,5,6,7,32,40,41}$ Use of the Internet has been shown to enrich the lives of isolated seniors, ${ }^{36}$ with some older adults reporting lower perceived life stress as a result of ICT use. ${ }^{43}$

Yet, some limited research has found no relationship between Internet connectedness and social isolation in older adults. ${ }^{26}$ Another study of the general population demonstrated that Internet use had a relatively limited impact on social relationships, ${ }^{18}$ with still other research indicating that ICT use was associated with an initial decline in social network size and increased loneliness. ${ }^{24}$ However, a followup study done in 2002 showed Internet users experienced positive effects on communication, social involvement, and well-being. ${ }^{23}$

The purpose of this study is to examine whether frequency of ICT use among older adults is associated with perceptions of (1) loneliness, (2) social isolation and (3) perceptions of the usefulness of the Internet in affecting quantity and quality of communication with social network ties.

\section{METHODS}

The data for this analysis comes from an ongoing randomized controlled trial intervention. In this study, assisted and independent living communities (AICs) were randomized into ICT, Attention Control, or True Control groups. Older adults living in AICs in the treatment arm were given 8 weeks of training in using computers and the Internet to communicate with family and friends (mainly through email and Facebook) and to find information. Participants in an "attention control" arm were involved in 8 weeks of activities unrelated to ICTs. Participants in a "true control" arm did not participate in any intervention activities. Participants from all three arms were surveyed 5 times over the course of one year before the 8 weeks, at the end of the 8 weeks, and at 3,6 , and 12 months after the end of the 8 weeks. Because the purpose of this paper is to examine the relationship between ICT use and outcomes such as loneliness, social isolation, and perceptions of the usefulness of the Internet for staying in touch, ICT users (participants with Internet access) from all three arms are included. Additionally, because there were such low numbers of ICT users at time 1, across the three arms $(n=33)$, post-test (immediately following the 8 weeks) data is used, reflecting all the relatively new ICT users in the ICT arm of the study. Thus, our sample includes all study participants who reported having Internet access, either on their own or as a result of the ICT intervention classes $(n=70)$.

Our outcomes include how use of the Internet has affected loneliness, social isolation, and the quality and quantity of communication with others. Loneliness was measured with a 3 -item version of the UCLA loneliness scale. ${ }^{20}$ Items in the scale $(a=.65)$ were:

a. How often do you feel that you lack companionship?

b. How often do you feel left out?

c. How often do you feel isolated from others?

with responses measured on a three point scale: 1Hardly ever, 2-Some of the time, 3-Often.

To measure social isolation, participants were also asked how much of the time they were bothered by the following things:

a. Not having a close companion

b. Not having enough friends

c. Not seeing enough of the people you feel close to.

The responses were coded as 0-Never, 1-A little of the time, 2-Some of the time, 3-Most of the time, 4All of the time. These items were analyzed individually.

Participants were asked a series of 7 questions regarding their perceptions of how Internet use had 
affected the quality and quantity of their communication with others. Participants were asked to what extent they agreed or disagreed with the following statements: Using the Internet has . . .

a. Made it easier for me to reach people

b. Contributed to my ability to stay in touch with people I know

c. Made it easier to meet new people

d. Increased the quantity of my communication with others

e. Made me feel less isolated

f. Helped me feel more connected to friends and family

g. Increased the quality of my communication with others.

The responses were coded as 1-Strongly Disagree, 2- Disagree, 3-Neither Agree nor Disagree, 4-Agree, 5-Strongly Agree.

ICT use was measured simply as frequency of going online. Participants were asked how often they went online with 0 coded as Never, 1-Once every few months, 2-About once a month, 3-Several times a month, 4-About once a week, 5-Several times a week. Only participants who reported having Internet access were included in the analysis, as those reporting no Internet access were not asked about their perceptions of how Internet use has affected their communications with others.

A series of OLS regression analyses were conducted using the communications and loneliness as the primary outcomes and using ICT use as the primary predictor variable. Analyses controlled for age, the number of social network members (friends and family to whom the participant felt close), study arm, and physical or emotional problems that would limit social interaction. While we would normally have controlled for race/ethnicity and gender, these controls were not included here as an overwhelming majority of the sample was white and female.

\section{REsULtS}

As noted, our sample was overwhelming white $(95.7 \%)$ and female $(81.4 \%)$, with a mean age of 84 years (full descriptive statistics are presented in Table 1). The mean frequency of going online was 3.41 (somewhere between 'several times a month' and 'about once a week'). Mean loneliness was 3.9. The sample contained 49 participants who had received ICT training and 21 who had not.

Results of OLS regression analyses showed a relationship between the frequency of going online and socio-emotional outcomes and between frequency of going online and selected Internetusefulness outcomes. Among the socio-emotional outcomes, a one-point increase in the frequency of going online was associated with a .220 point decrease in loneliness scores $(p<=.001)$ (full results presented in Table 2). After controlling for the number of friends and family, physical/emotional social limitations, age, and study arm, the association remained, with a one-point increase in the frequency of going online being associated with a .236 point decrease in loneliness scores.

Table 1. Descriptive Statistics $(n=70)$

\begin{tabular}{lc}
\hline & $\begin{array}{c}\text { Mean (SD) } \\
\text { or } \\
\text { Percentage }\end{array}$ \\
Sex & 18.6 \\
$\quad$ Male & 81.4 \\
$\quad$ Female & $84.0(6.1)$ \\
Age & \\
Race & 95.7 \\
$\quad$ White & 4.3 \\
Other & $3.4(2.0)$ \\
Frequency of Going Online & $3.9(1.2)$ \\
Loneliness & \\
\hline
\end{tabular}

Likewise, going online more often was associated with a decrease in the amount of time respondents were bothered by not having a close companion and by not seeing enough of the people they are close to. A one-point increase in online frequency was associated with a .153 point decrease in the amount of time respondents were bothered by not having a close companion. This relationship held even after the controls were entered, with a one-point increase in online frequency being associated with a .178 point decrease in amount of time being bothered by not having a close companion. Both of these associations were statistically significant at the .05 level. Similarly, a one-point increase in online frequency was associated with a .189 point decrease in the amount of time respondents were bothered by not seeing enough of the people they are close to. This relationship, too, held in the presence of the controls with a one-point increase in frequency of going online being associated with a .198 point decrease in the amount of time respondents reported being bothered by not seeing enough of those they are close to. Both of these relationships were statistically significant at the .01 level. Frequency of going online was not associated with the amount of time respondents were bothered by not having enough close friends.

Among the Internet outcome measures there were only two relationships of note, both of which were statistically significant at the .05 level before controls, but which barely missed the .05 cutoff in the presence of controls (full results presented in Table 3). In terms of agreement with the statement 
Table 2. OLS Regressions (Socio-Emotional Outcomes) ( $n=70)$

\begin{tabular}{|c|c|c|c|c|c|c|c|c|}
\hline & \multicolumn{2}{|c|}{$\begin{array}{l}\text { Loneliness (Score Range: } \\
\qquad 3-9 \text { ) }\end{array}$} & \multicolumn{2}{|c|}{$\begin{array}{l}\text { Bothered by Not Having } \\
\text { Close Companion }\end{array}$} & \multicolumn{2}{|c|}{$\begin{array}{c}\text { Bothered by Not Having } \\
\text { Enough Friends }\end{array}$} & \multicolumn{2}{|c|}{$\begin{array}{c}\text { Bothered by Not Seeing } \\
\text { Enough of People Close } \\
\text { To }\end{array}$} \\
\hline & Model 1 & Model 2 & Model 1 & Model 2 & Model 1 & Model 2 & Model 1 & Model 2 \\
\hline Constant & $4.67^{* * *}$ & $10.19^{\star * *}$ & $2.57^{* * *}$ & $4.73^{*}$ & $1.82^{\star * *}$ & $4.19^{* \star *}$ & $2.97^{* \star *}$ & $4.84^{* *}$ \\
\hline Frequency of Going Online & $-.220^{\star * \star}$ & $-.236^{\star * *}$ & $-.153^{*}$ & $-.178^{*}$ & -.064 & -.077 & $-.189^{\star *}$ & $-.198^{* *}$ \\
\hline Number of Family/Friends & - & $-.065^{*}$ & - & -.028 & - & $-.037^{\dagger}$ & - & -.023 \\
\hline Physical/Emotional Social Limitation & - & .056 & - & -.061 & - & -.003 & - & -.069 \\
\hline Age & - & $-.056^{*}$ & - & -.020 & - & -.025 & - & -.018 \\
\hline In ICT Group & - & -.182 & - & -.055 & - & .178 & - & -.024 \\
\hline In AC Group & - & -.094 & - & -.319 & - & .250 & - & .054 \\
\hline Model $F$ & $11.10^{\star * *}$ & $4.67^{* * *}$ & $6.22^{*}$ & 1.47 & 1.83 & 1.58 & $10.42^{* *}$ & $2.07^{\dagger}$ \\
\hline$x_{0}$ & .13 & .24 & .07 & .04 & .01 & .05 & .12 & .09 \\
\hline
\end{tabular}

Table 3. OLS Regressions (Using the Internet has . . .) (n=54)

\begin{tabular}{|c|c|c|c|c|c|c|c|c|}
\hline & \multicolumn{2}{|c|}{$\begin{array}{l}\text { Made it easier to reach } \\
\text { people }\end{array}$} & \multicolumn{2}{|c|}{$\begin{array}{l}\text { Contributed to ability to } \\
\text { stay in touch }\end{array}$} & \multicolumn{2}{|c|}{$\begin{array}{l}\text { Made it easier to meet new } \\
\text { people }\end{array}$} & \multicolumn{2}{|c|}{$\begin{array}{c}\text { Increased quantity of } \\
\text { communication with } \\
\text { others }\end{array}$} \\
\hline & Model 1 & Model 2 & Model 1 & Model 2 & Model 1 & Model 2 & Model 1 & Model 2 \\
\hline Constant & $3.05^{\star \star *}$ & $4.78^{* *}$ & $2.82^{* * *}$ & $4.60^{* *}$ & $2.17^{* \star *}$ & $4.07^{*}$ & $2.71^{* \star *}$ & $4.30^{* *}$ \\
\hline Frequency of Going Online & .171 & .095 & $.241^{*}$ & $.194^{\dagger 1}$ & .168 & .113 & $.249^{* *}$ & $.194^{\dagger 2}$ \\
\hline Number of Family/Friends & - & .037 & - & .017 & - & $.041^{\dagger}$ & - & .029 \\
\hline Physical/Emotional Social Limitation & - & -.157 & - & -.087 & - & -.051 & - & -.129 \\
\hline Age & - & -.018 & - & -.019 & - & -.022 & - & -.017 \\
\hline In ICT Group & - & -.175 & - & -.066 & - & -.176 & - & -.145 \\
\hline In AC Group & - & -.916 & - & -.537 & - & -.508 & - & -.479 \\
\hline Model $F$ & 2.68 & 1.95 & $6.91^{*}$ & 1.74 & 2.17 & 1.13 & $7.23^{\star *}$ & $2.20^{\dagger}$ \\
\hline $\mathrm{R}^{2}$ & .03 & .10 & .10 & .08 & .02 & .02 & .11 & .12 \\
\hline
\end{tabular}


Table 3 cont. OLS Regressions (Using the Internet has . . .) ( $n=54$ )

\begin{tabular}{|c|c|c|c|c|c|c|}
\hline & \multicolumn{2}{|c|}{ Made me feel less isolated } & \multicolumn{2}{|c|}{$\begin{array}{l}\text { Helped me feel more } \\
\text { connected to friends and } \\
\text { family }\end{array}$} & \multicolumn{2}{|c|}{$\begin{array}{l}\text { Increased the quality of } \\
\text { my communication }\end{array}$} \\
\hline & Model 1 & Model 2 & Model 1 & Model 2 & Model 1 & Model 2 \\
\hline Constant & $3.39^{\star * *}$ & $4.98^{* *}$ & $3.53^{\star * *}$ & $3.82^{* *}$ & $3.56^{* * *}$ & $4.11^{* *}$ \\
\hline Frequency of Going Online & .094 & .054 & .109 & .049 & .057 & .019 \\
\hline Number of Family/Friends & - & $.048^{*}$ & - & .014 & - & .003 \\
\hline Physical/Emotional Social Limitation & - & .049 & - & -.124 & - & $-.166^{\dagger}$ \\
\hline Age & - & -.023 & - & .000 & - & -.003 \\
\hline In ICT Group & - & -.002 & - & -.059 & - & -.046 \\
\hline In AC Group & - & -.689 & - & -.901 & - & -.394 \\
\hline Model $F$ & .778 & 1.18 & 1.68 & 1.33 & .395 & .768 \\
\hline 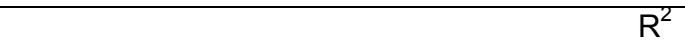 & .00 & .02 & .01 & .04 & -.01 & -.03 \\
\hline
\end{tabular}


that "using the Internet has contributed to my ability to stay in touch with people I know", a one-point increase the frequency of going online was associated with a .241 point increase in agreement that the Internet had contributed to the ability to stay in touch. This association was statistically significant at the .05 level. Once controls were included, however, the relationship was weakened such that a one-point increase in online frequency was associated with a .194 point increase in agreement with the statement that the Internet had contributed to the respondents' ability to stay in touch ( $p$. = .054).

A similar change occurred in the analysis of respondents' agreement with the statement that "using the Internet has increased the quantity of my communication with others." Before controls a onepoint increase in the frequency of going online was associated with a .249 point increase in agreement that the Internet had increased the quantity of communication. The relationship was statistically significant at the .01 level. Once again, after the inclusion of controls, the relationship weakened, with a one-point increase in online frequency being associated with a .194 point increase in agreement that the Internet had increased the quantity of the respondents' communication with others. This relationship, with controls, also missed the cutoff for statistical significance, with an exact p-value of .051. Frequency of going online was not associated with a change in agreement with the statements that using the Internet had "made it easier to reach people," made it easier to meet new people," "made me feel less isolated," "helped me feel more connected to friends and family," or "increased the quality of my communication with others."

\section{DISCUSSION AND LIMITATIONS}

Results of this study suggest that the frequency of going online impacts loneliness and perceptions of social isolation, with higher frequency being associated with lower levels of loneliness and social isolation among older adults in assisted and independent living communities. These results support prior research showing that Internet use positively impacts quality of life among older adults. $^{5,9,10,35,36,39}$ However, it is interesting that older adults in this study do not perceive that using the Internet has made it easier for them to reach people, meet new people, helped them to feel more connected to friends and family, or increased the quality of their communication. They do, however, perceive that using the Internet has contributed to their ability to stay in touch and has increased the quantity of communication with others. The results of this study suggest that further research is needed to better ascertain when older adults in different types of living communities may perceive and actually receive the most benefits from using a variety of types of ICTs.

Limitations of the current study include the small sample size, the lack of diversity in terms of gender and race/ethnicity, and that the study was only conducted in assisted and independent living communities in Alabama. Further research is needed on how technology usage may impact older adults not living in AICs and how these processes may vary as a function of gender, race/ethnicity, severity of health impairment, and region of the country.

In sum, this research indicates that Internet usage has positive benefits for older adults living in assisted and independent living communities. Given that this population experiences high rates of loneliness and depression, encouraging older adults to begin using the Internet to communicate with others could help to enhance social contact and decrease loneliness and social isolation.

\section{References}

1. Adams, R.G., \& Stevenson, M.L., "A Lifetime of Relationships Mediated by Technology", In F.R. Lang, and K.L. Fingerman (Eds.), Growing Together: Personal Relationships Across the Lifespan, pp. 368-394. Cambridge, UK: Cambridge University Press, 2004.

2. Barnett, K., \& Adkins, B., "Computers: Community for Aging Women in Australia", Women \& Environments, Spring/Summer, 2001.

3. Blit-Cohen, E., \& Litwin, H., "Elder Participation in Cyberspace: A Qualitative Analysis of Israeli Retirees", Journal of Aging Studies, Vol. 18, pp. 385-398, 2004.

4. Boase, J., Horrigan, J.B., Wellman, B., Rainie, L., "The Strength of Internet Ties: The Internet and Email Aid Users in Maintaining Their Social Networks and Provide Pathways to Help When People Face Big Decisions", Retrieved March 4, 2012 from Pew Internet and American Life Project Web site: http://www.pewinternet.org/ /media//Files/Reports/ 2006/PIP_Internet_ties.pdf.pdf, 2006.

5. Bradley, $\bar{N}$. \& Poppen, W., "Assistive Technology, Computers and Internet May Decrease Sense of Isolation for Homebound Elderly and Disabled Persons", Technology and Disability, Vol. 15, pp. 19-25, 2003.

6. Climo, J.J., "Images of Aging in Virtual Reality: The Internet and the Community of Affect", Generations, Fall, 2001.

7. Cody, M.J., Dunn, D., Hoppin, S., \& Wendt, P., "Silver Surfers: Training and Evaluating Internet Users Among Older Adult Learners", Communication Education, Vol. 48, 1999. 
8. Cornwell, E.Y., \& Waite, L.J., "Social Disconnectedness, Perceived Isolation, and Health Among Older Adults", Journal of Health and Social Behavior, Vol. 50(1), pp. 31-48, 2009.

9. Cotten, S.R., "Using ICTs to Enhance Quality of Life Among Residents of Independent Living and Assisted Living Communities", Presented at the Gerontological Society of America Annual Meeting, New Orleans, LA, November 2010.

10. Cotten, S.R., Ford, G., Ford, S., \& Hale, T.M., "Internet Use and Depression among Older Adults", Computers in Human Behavior, Vol. 28, pp. 496-499, 2012.

11. Czaja, S.J., \& Barr, R.A., "Technology and the Everyday Life of Older Adults", The Annals of the American Academy, 1989.

12. Dickinson, A. and Gregor, P., "Computer Use Has No Demonstrated Impact on the Well-being of Older Adults", International Journal of HumanComputer Studies, Vol. 64, pp. 744-753, 2006.

13. Fox, S., "Older Americans and The Internet: Just 22\% Go Online, but Their Enthusiasm for Email and Search May Inspire Their Peers to Take the Leap", Retrieved March 4, 2012 from Pew Internet and American Life Project Web site: http://www.pewinternet.org/ /media//Files/Reports/ 2004/PIP_Seniors_Online_2004.pdf, 2004.

14. Fox, S., Rainie, L., Larsen, E., Horrigan, J., Lenhart, A., Spooner, T., \& Carter, C., "Wired Seniors: A Fervent Few, Inspired by Family Ties", Retrieved March 4, 2012 from Pew Internet and American Life Project Web site: http://www.pewlnternet.org/ /media//Files/Reports/ 2001/PIP_Wired_Seniors_Report.pdf, 2001.

15. Gatto, S.L., Tak, S.H., "Computer, Internet, and EMail Use Among Older Adults: Benefits and Barriers", Educational Gerontology, Vol. 34, pp. 800-811, 2008.

16. Havens, B., Hall, M., Sylvestre, G., \& Jivan, T., "Social Isolation and Loneliness: Differences between Older Rural and Urban Manitobans", Canadian Journal on Aging, Vol. 23(2), pp. 129140, 2004.

17. Heylen, L., "The Older, the Lonelier? Risk Factors for Social Loneliness in Old Age", Ageing \& Society, Vol. 30, pp.1177-1196, 2010.

18. Hlebec, V., Lozar Manfreda, K., \& Vehovar, V., "The Social Support Networks of Internet Users", New Media \& Society, Vol. 8, pp. 9-32, 2006.

19. Hogeboom, D.L., McDermott, R.J., Perrin, K.M., Osman, H., \& Bell-Ellison, B.A., "Internet Use and Social Networking among Middle Aged and Older Adults", Educational Gerontology, Vol. 36, pp. 93111, 2010.

20. Hughes, M.E., Waite, L.J., Hawkley, L.C., \& Cacioppo, J.T., "Loneliness in Large Surveys: Results from Two Population-Based Studies", Research on Aging, Vol 26(6), pp. 655-672, 2004.

21. Jylha, M., "Old Age and Loneliness: CrossSectional and Longitudinal Analyses in the
Tampere Longitudinal Study on Aging", Canadian Journal on Aging, Vol. 23(2), pp. 157-168, 2004.

22. Kanayama, T., "Ethnographic Research on the Experience of Japanese Elderly People Online", New Media \& Society, Vol. 5, pp. 267-288, 2003.

23. Kraut, R., Kiesler, S., Boneva, B., Cummings, J., Helgeson, V., \& Crawford, A. "Internet Paradox Revisited", Journal of Social Issues, Vol. 58(1), pp. 49-74, 2002.

24. Kraut, R., Patterson, M., Lundmark V., Kiesler S., Mukopadhyay, T., \& Scherlis, W., Internet Paradox: A Social Technology that Reduces Social Involvement and Psychological Well-being?", American Psychologist, Vol. 53, pp. 1017-1031, 1998.

25. Locher, J.L., Ritchie, C.S., Roth, D.L., Sawyer Baker, P., Bodner, E.V., \& Allman, R.M., "Social Isolation, Support, and Capital and Nutritional Risk in an Older Sample: Ethnic and Gender Differences", Social Science \& Medicine, Vol. 60, pp. 747-761, 2005.

26. Loges, W., \& Jung, J., "Exploring the Digital Divide: Internet Connectedness and Age", Communication Research, Vol. 28, pp. 536-562, 2001.

27. McMellon, C.A., \& Schiffman, L.G., "Cybersenior Empowerment: How Some Older Individuals are Taking Control of Their Lives", Journal of Applied Gerontology, Vol. 21, pp. 157-175, 2002.

28. Morris, A., Goodman, J., \& Brading, H., "Internet Use and Non-Use: Views of Older Users", Universal Access in the Information Society, Vol. 6, pp. 43-57, 2007.

29. Nimrod, G., "Seniors' Online Communities: A Qualitative Content Analysis", The Gerontologist, Vol. 50(3), pp. 382-392, 2009.

30. Perlman, D., "European and Canadian Studies of Loneliness among Seniors", Canadian Journal on Aging, Vol. 23(2), pp. 181-188, 2004.

31. Perlman, D., \& Peplau, L.A., "Loneliness", In H. Friedman (Ed.), Encyclopedia of Mental Health, Vol. 2, pp. 571-581. San Diego, CA: Academic Press, 1998.

32. Pfeil, U., "Online Social Support for Older People", Accessibility and Computing, Vol. 88, pp. 3-8, 2007.

33. Russell, C., Campbell, A., \& Hughes, I., "Ageing, Social Capital, and the Internet: Findings from an Exploratory Study of Australian 'Silver Surfers'”, Australasian Journal on Aging, Vol. 27, pp. 78-82, 2008.

34. Russell, D., "Living Arrangements, Social Integration, and Loneliness in Later Life: The Case of Physical Disability", Journal of Health and Social Behavior, Vol. 50(4), pp. 460-475, 2009.

35. Sum, S., Matthews, M.R., Pourghasem, M., \& Hughes, I., "Internet Technology and Social Capital: How the Internet Affects Seniors' Social Capital and Well-being", Journal of ComputerMediated Communication, Vol. 14, pp. 202-220, 2008. 
36. Swindell, R., "Using the Internet to Build Bridges to Isolated Older People", Australasian Journal on Aging, Vol. 19, pp. 38-40, 2008.

37. The Henry J. Kaiser Family Foundation, "e-Health and the Elderly: How Seniors Use the Internet for Health Information", Retrieved March 4, 2012 from Pew Internet and American Life Project Web site: http://www.kff.org/entmedia/upload/e-Health-andthe-Elderly-How-Seniors-Use-the-Internet-for-

Health-Information-Key-Findings-From-a-NationalSurvey-of-Older-Americans-Survey-Report.pdf, 2005.

38. Wenger, C.G., \& Burholt, V., "Changes in Levels in Social Isolation and Loneliness Among Older People in a Rural Area: A Twenty-Year Longitudinal Study", Canadian Journal on Aging, Vol. 23(2), pp. 115-127, 2004.

39. Winstead, V., Anderson, W.A., Yost, E.A., Cotten, S.R., Warr, A., \& Berkowsky, R.W., "You Can Teach an Old Dog New Tricks: A Qualitative Analysis of How Residents of Senior Living Communities May Use the Web to Overcome Spatial and Social Barriers", Journal of Applied Gerontology, 2012.

40. White, H., McConnell, E., Clipp, E., Branch, L.G., Sloane, R., Pieper, C., \& Box, T.L., "A Randomized Controlled Trial of the Psychosocial Impact of Providing Internet Training and Access to Older Adults", Aging and Mental Health, Vol. 6, pp. 213221, 2002.

41. White, H., McConnell, E., Clipp, E., L. Bynum, L., C. Teague, C., L. Navas, L., S. Craven, S., \& H. Halbrecht, H., "Surfing the Net in Later Life: A Review of the Literature and Pilot Study of Computer Use and Quality of Life", Journal of Applied Gerontology, Vol. 18, pp. 358-378, 1999.

42. White, J., \& Weatherall, A., "A Grounded Theory Analysis of Older Adults and Information Technology", Educational Gerontology, Vol. 26, pp. 371-386, 2000.

43. Wright, K., "Computer-Mediated Social Support, Older Adults, and Coping", Journal of Communication, Vol. 50, pp.100-118, 2000.

44. Yang, K., \& Victor, C.R., "The Prevalence of and Risk Factors for Loneliness among Older People in China", Ageing \& Society, Vol. 28, pp. 305-327, 2008. 